\title{
TEMPORAL AND SPATIAL CHARACTERISTICS OF EXTREME TEMPERATURE IN THE MIDDLE REACH OF THE YELLOW RIVER, CHINA
}

\author{
FENG, K. P. ${ }^{1,2,3}-$ TIAN, J. C. ${ }^{1,2,3 *}-$ WANG, Z. P. ${ }^{4}$ \\ ${ }^{1}$ School of Civil and Hydraulic Engineering, Ningxia University, Yinchuan, China \\ ${ }^{2}$ Engineering Research Center for Efficient Utilization of Water Resources in Modern \\ Agriculture in Arid Regions, Yinchuan, China \\ ${ }^{3}$ Ningxia Research Center of Technology on Water-Saving Irrigation and Water Resources \\ Regulation, Yinchuan, China \\ ${ }^{4}$ School of Mathematics and Statistics, Ningxia University, Yinchuan 750021, China \\ *Corresponding author \\ e-mail:slxtjc@163.com \\ (Received 23 $3^{\text {rd }}$ Apr 2019; accepted $4^{\text {th }}$ Jul 2019)
}

\begin{abstract}
Yellow River is a production area for main grain crops in China and is also an emerging industrial cluster. this study adopts meteorological data from 1951 to 2014 provided by 73 national ordinary stations in the study area, combines Kendall-tau non-parametric test method, Sen's slope estimation method and Savitzky-Golay smoothing filtering method based on sub-regions divided by fuzzy clustering method and analyzes the variation trend of extreme temperature indexes. The results show that: (1) in the middle reach of Yellow River, the variation trend of extreme temperature events is basically similar, but the intensity is different, and the spatial distribution is inconsistent. (2) On time scale, an upward trend has been found in extreme temperature events in the past 60 years. (3) On spatial scale, the change rate of multiple indexes in the arid sub-region is greater than that of those in the humid sub-region; the proportion of meteorological stations with significant index changes in the arid region is higher than that in the humid sub-region. Some indexes have different trends in small areas, which may be caused by local microclimates in urban heat islands and hilly areas, but further analysis and verification is also required.
\end{abstract}

Keywords: fuzzy clustering, Kendall-tau, Sen's slope estimation, Savitzky-Golay smoothing filtering, extreme temperature

\section{Introduction}

More than half a century in the past, scholars at home and abroad have conducted a lot of research work on extreme climate events in different regions of the world and have achieved research results of different depths. In early 2014, Science published 7 papers in a row to discuss the "the Challenge of Climate Science" and elaborate on some core issues of current climate and hydrology sciences, including the issue of "regional climate and extreme events". The paper believed that an important trend of warming research is to reflect global warming in the research on regional climate and extreme events, but the research needs to be further developed, where great difficulties also exist (Wang et al., 2014a; Horton et al., 2015). At present, domestic and international researches focus mainly on the observational facts of extreme climate. The fifth assessment report of the UN Intergovernmental Panel on Climate Change (IPCC) has summed up the observations and research findings of extreme temperature and precipitation events in full length. Many studies show that extreme precipitation events 
are very sensitive to the global climate change, and minor changes in the climate may cause greater changes in the frequency and intensity of extreme weather events (Alexander, 2016; Diffenbaugh et al., 2017; Mooshammer et al., 2017; Grotjahn et al., 2016; Ma et al., 2015).

The middle reach of Yellow River is located in the confluence of the Loess Plateau, Ordos Plateau and Inner Mongolia Plateau; where plains, deserts, mountains, platforms, lakes and wetlands are intertwined, topography and landform are complex, terrain changes greatly and the structure of the underlying surface is complex. The area is a major producing area of main gain crops and industrial crops in China and is also an emerging industrial cluster. Extreme temperature events may have an impact on industrial and agricultural production and urban development in the area (Nie et al., 2015). In recent years, researchers have conducted a research on temporal and spatial variation characteristics, variation trends and cases of formation of extreme temperature events in mainland China (Zhou et al., 2010), northern and southern China (Zhai et al., 2003; Tang et al., 2014), certain watersheds (Wang et al., 2013) and certain provinces (Shen et al., 2012; Chen et al., 2012, 2011; Zhang et al., 2014; Li et al., 2015; Wang et al., 2016, 2012), respectively. However, the research on extreme temperature events in the middle reach of Yellow River is still insufficient so far.

Based on previous researches, this study adopts the daily temperature data of 73 meteorological stations and uses the internationally used extreme temperature event indexes to conduct an in-depth research on the temporal and spatial changes in extreme temperature events in the middle reach of Yellow River, reveal the change characteristics and trends, hoping to provide a reference for water circulation, water resource management, ecological vulnerability assessment and hydrogeological hazard warning and other researches in the area under extreme climate conditions.

\section{Data and methodology}

\section{Data}

This study adopts the temperature data from 1951 to 2014 of 73 national ordinary stations in the middle reach of Yellow River provided by China Meteorological Data Network (http://data.cma.cn/, China Surface Dataset Daily Value Dataset V3.0). The meteorological data selected has passed quality control, including inspection of climate threshold value or allowable value); inspection of extreme value of station; internal consistency inspection of set value, daily average and daily extremum; temporal and spatial consistency inspection and other measures. In addition, the distribution of meteorological stations is shown in Figure 1.

\section{Research method}

\section{Definition and calculation of extreme temperature indexes}

The definition of extreme temperature indexes in this research is based on the "climate change detection and indexes" determined by CCI, WCRP, CLIVAR and ETCCDMI. These indexes and their calculation methods have been widely used in the world, and the research results also reflect that these indexes are characterized by good regional adaptability, low noise, low extremity and strong significance (Li et al., 2012; Zhao et al., 2015). There are 29 indexes in this series, including temperature and precipitation. This paper selects 18 temperature indexes to analyze the extreme 
temperature events in the middle reach of Yellow River, and specific indexes and definitions are shown in Table 1. The indexes are calculated using RClimDex1.1 software. In the process of calculation, quality inspection and control are conducted on the said meteorological data including outliers and error values. Meanwhile, this paper also adopts new international climate change benchmarks (Zhang et al., 2014).

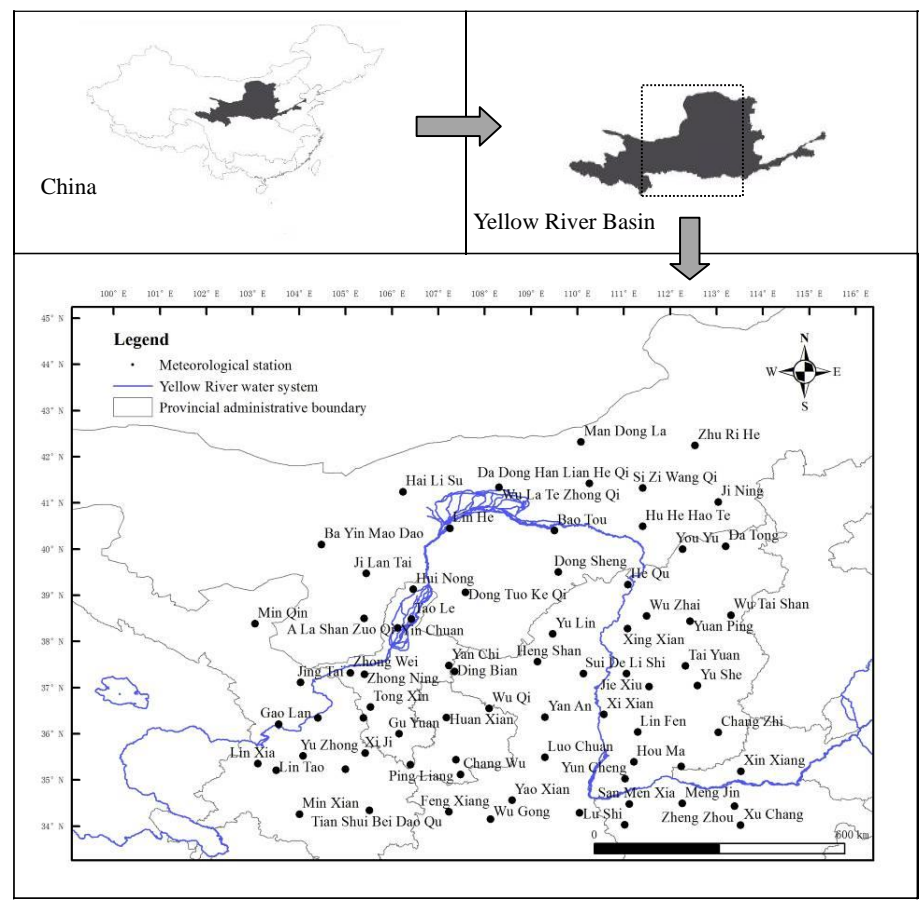

Figure 1. Meteorological stations in the middle reach of Yellow River

Table 1. Definitions of extreme temperature indexes

\begin{tabular}{c|c|c}
\hline $\begin{array}{c}\text { Abbreviation } \\
\text { of index }\end{array}$ & Definition & Unit \\
\hline $\begin{array}{c}\text { DTR } \\
\text { TMAXmean }\end{array}$ & $\begin{array}{c}\text { Difference between daily maximum temperature and daily minimum temperature } \\
\text { AMINmean }\end{array}$ & $\begin{array}{c}{ }^{\circ} \mathrm{C} \\
\text { Average value of annual/monthly/daily maximum temperature } \\
\text { Average value of annual/monthly/daily minimum temperature } \\
\text { TNx }\end{array} \quad$ Minimum value of annual/monthly/daily minimum temperature \\
TXn & Maximum value of annual/monthly/daily minimum temperature & ${ }^{\circ} \mathrm{C}$ \\
TXx & Minimum value of annual/monthly/daily maximum temperature & ${ }^{\circ} \mathrm{C}$ \\
FD0 & Maximum value of annual/monthly/daily maximum temperature & ${ }^{\circ} \mathrm{C}$ \\
ID0 & Number of days in a year whose minimum temperature is below $0{ }^{\circ} \mathrm{C}$ & ${ }^{\circ} \mathrm{C}$ \\
SU25 & Number of days in a year whose maximum temperature is below $0{ }^{\circ} \mathrm{C}$ & $\mathrm{d}$ \\
TN10p & Number of days whose daily maximum temperature is above $25{ }^{\circ} \mathrm{C}$ & $\mathrm{d}$ \\
TN90p & Number of days whose daily minimum temperature is below $10 \%$ tantile & $\mathrm{d}$ \\
TR20 & Number of days in a year whose daily minimum temperature is above $20{ }^{\circ} \mathrm{C}$ & $\mathrm{d}$ \\
TX10p & Number of days whose daily maximum temperature is below $10 \%$ tantile & $\mathrm{d}$ \\
TX90p & Number of days whose daily maximum temperature is above $90 \%$ tantile & $\mathrm{d}$ \\
WSDI & Number of days whose maximum temperature is $90 \%$ tantile for 6 days in a row & $\mathrm{d}$ \\
CSDI & Number of days whose minimum temperature is $10 \%$ tantile for 6 days in a row & $\mathrm{d}$ \\
GSL & Time span during which the temperature is above or below $5{ }^{\circ} \mathrm{C}$ for 6 days in a row & $\mathrm{d}$ \\
\hline
\end{tabular}




\section{Fuzzy clustering analysis}

Clustering analysis is a multivariate statistical analysis method, which classifies individuals based on their several characteristics, so that individuals of the same category have a higher homogeneity while individuals of different categories have a higher heterogeneity. When it comes to dealing with actual classification problems, varying degrees of fuzziness is always seen because the boundaries of individual categories are not always clear and exact. When clustering involves fuzzy boundaries between individuals, a fuzzy clustering analysis method is usually used, which is established on fuzzy mathematics. Fuzzy C-Means (FCM for short) was proposed by Bezkek in 1981. The impact of different number of categories $c$ on classification results is highly significant. To evaluate the classification effect under different $c$ values in a scientific way, the predecessors have done a lot of research work and defined a number of evaluation indexes (see Eqs. 1-4) to guide the specific classification process. Assuming that different $c$ values are determined according to those indexes (Eqs. 1-4), the smaller $c$ value shall prevail if different $c$ values have similar classification effect (Qi et al., 2015).

Partition coefficient (PC):

$$
P Q c)=\frac{1}{N} \sum_{i=1}^{c} \sum_{j=1}^{N} u_{i j}
$$

Classification entropy (CE):

$$
\mathcal{C}(c)=\frac{1}{N} \sum_{i=1}^{c} \sum_{j=1}^{N} u_{i j} \log \left(u_{i j}\right)
$$

Partition index (SC):

$$
S Q c)=\sum_{i=1}^{c} \frac{\sum_{k=1}^{N}\left(u_{i j}\right)^{m}\left\|x_{j}-v_{i}\right\|^{2}}{N_{i} \sum_{k=1}^{c}\left\|v_{k}-v_{i}\right\|^{2}}
$$

Separation index $(\mathrm{S})$ :

$$
S(c)=\frac{\sum_{i=1}^{c} \sum_{k=1}^{N}\left(u_{i j}\right)^{2}\left\|x_{j}-v_{i}\right\|^{2}}{N \min _{i j}\left\|v_{k}-v_{i}\right\|^{2}}
$$

\section{Analysis method of variation trend of extreme temperature indexes}

Meteorological data belongs to time series. For the trend analysis of time series, a linear regression method is usually used, but such method directly calculates the slope based on the actual data value, which is greatly affected by the abnormal value. Sen's slope estimation algorithm has strong anti-noise performance, but it cannot be used to make a significant judgment of sequence trend. The Kendall-tau non-parametric test 
method does not require the sample to follow a certain distribution, allows the existence of missing values and can achieve significant judgments, but it cannot be used to obtain the slope of the sequence (ZHAI et al., 2003). Therefore, Kendall-tau non-parametric test method and Sen's slope estimation method are combined in this paper to make full use of their respective advantages, so that they can better serve the analysis of changes in extreme temperature indexes.

\section{Savitzky-Golay smoothing filtering method}

To more clearly extract and demonstrate the variation trend of extreme temperature indexes, the Savitzky-Golay smoothing filtering method is used in this paper. The method was proposed by Savitzky and Golay in 1964, which is a filtering method based on local polynomial least squares fitting in the time domain, whose prominent advantage is that it can ensure that signal shape and width remains unchanged at the time of simple and rapid filtering of noise (Cai et al., 2011;). In addition, the SavitzkyGolay smoothing filter in this study uses 7 points 2 times as the polynomial parameter.

\section{Results and analysis}

\section{FCM-based climate division}

To facilitate the analysis of the overall situation of the extreme temperature indexes in the middle reach of Yellow River on time scale, it is required to summarize 73 meteorological stations as specific climate regions. As mentioned before, the middle reach of Yellow River is located in the confluence of three major plateaus, where the terrain is complex as well as the structure of the underlying surface. It is obviously inappropriate to directly average 73 meteorological stations above and generalize the entire the middle reach of Yellow River as one region. Therefore, proper zoning is required. There are actually a lot of methods for climate zoning, the fuzzy clustering method (FCM) is used in this paper.

Combined with the natural conditions of the geographical location of the research area, latitude and longitude, altitude, average temperature and maximum and minimum temperature of the meteorological stations are regarded as characteristic values to perform clustering analysis on 73 meteorological stations in the middle reach of Yellow River. The number of divisions is preliminarily estimated to be $c=2$ or $c=3$. By selecting different $c$ values, FCM can obtain corresponding membership matrix. According to the relationship reflected in the matrix, the classification results shall be plotted when $c=2$ or $c=3$ (see Fig. 2). On this basis, the most reasonable number of divisions shall be analyzed in combination with 7 different indexes listed in Table 3 . In addition, it can be seen from Figure 2 that more stations are not classified in the middle reach of Yellow River when $c=3$; while the classification shows good results when $c=2$.

To more intuitively express the FCM climate divisions in the middle reach of Yellow River, the classification results are represented in a map (see Fig. 3). It can be clearly observed that 73 stations are classified into 2 different climate divisions along the line of "Yuanping - Xing County_Suide-Yan'an-Pingliang - Tianshui", and the line is very close to China's $400 \mathrm{~mm}$ equivalent precipitation line and "HuHuanYong Line", which also fully indicates that it is reliable and reasonable to apply the fuzzy clustering algorithm to climate division in this paper. By referring to the significance of the 
$400 \mathrm{~mm}$ equivalent precipitation line, this paper defines 2 different climate divisions in the middle reach of Yellow River obtained by FCM clustering analysis as "arid and semi-arid sub-region" and "humid and semi-humid sub-region", respectively. For the purpose of conciseness, they are referred to as "arid sub-region" and "humid subregion", respectively.
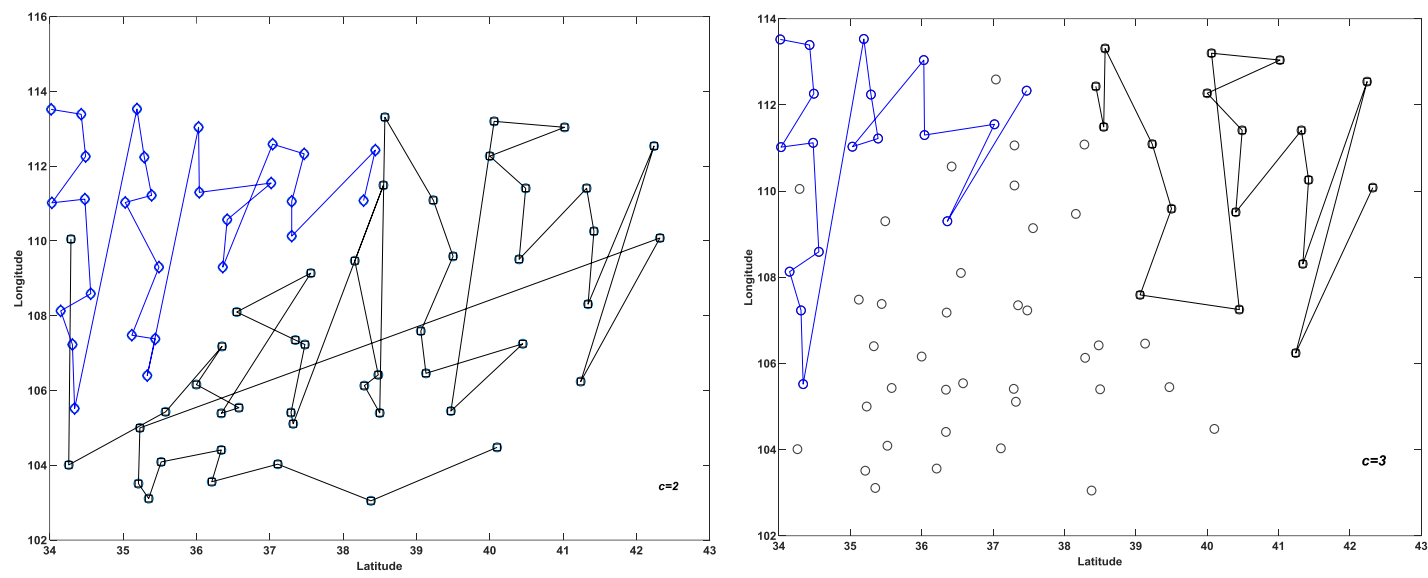

Figure 2. FCM analysis of meteorological stations

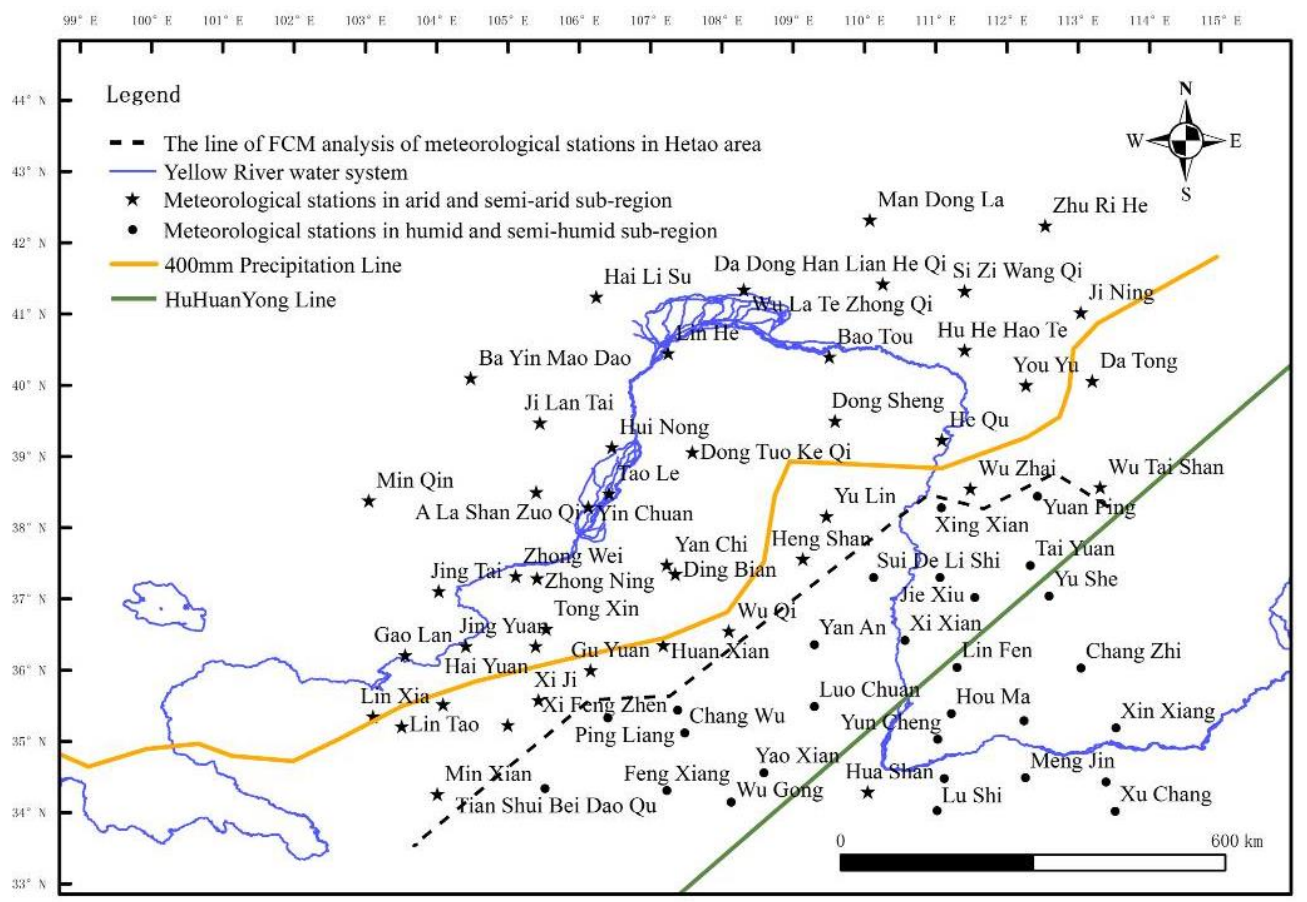

Figure 3. FCM analysis results of meteorological stations in the middle reach of Yellow River

\section{Temporal and spatial variation of extreme temperature indexes}

Variation of DTR, TMAXmean, TMINmean, TNn, TNX, TXn and TXx indexes

In the past 60 years, the daily temperature range (DTR) has dropped significantly, while the average maximum temperature TMAXmean and average minimum 
temperature TMINmean have increased significantly, and shown an obvious stage (see Fig. $4 a, c$ and $e$ ). DTR continued to decline around 1951-2000, TMAXmean and TMINmean continued to rise, but the variation trend of indexes began to slow down after 2000. These three indexes had the same rate of change in the arid and humid subregions, reaching $0.1{ }^{\circ} \mathrm{C} / 10 \mathrm{a}, 0.2^{\circ} \mathrm{C} / 10 \mathrm{a}$, and $0.3{ }^{\circ} \mathrm{C} / 10 \mathrm{a}$, respectively (see Table 3). The rate of increase of average minimum temperature is higher than that of average maximum temperature, which is the primary reason for the significant decrease in daily temperature range. Viewed from spatial distribution, DTR shows a significant downward trend in most meteorological stations, and the average maximum temperature and average minimum temperature show an obvious upward trend in the entire the middle reach of Yellow River (see Fig. $4 b, d$ and $f$ ).

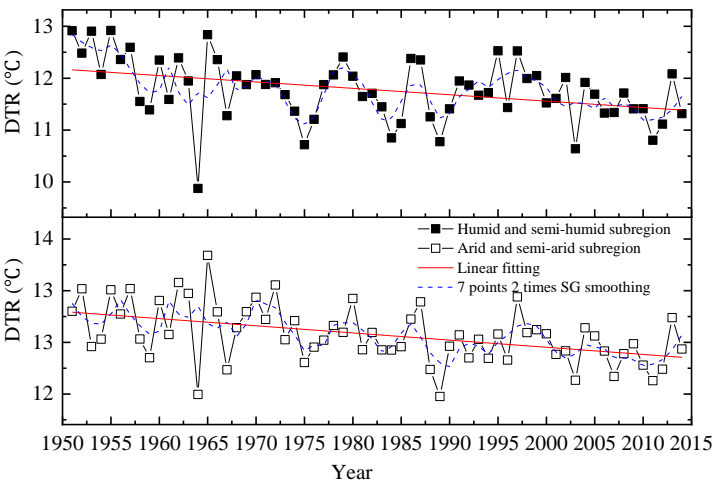

(a) Interannual variation of DTR index

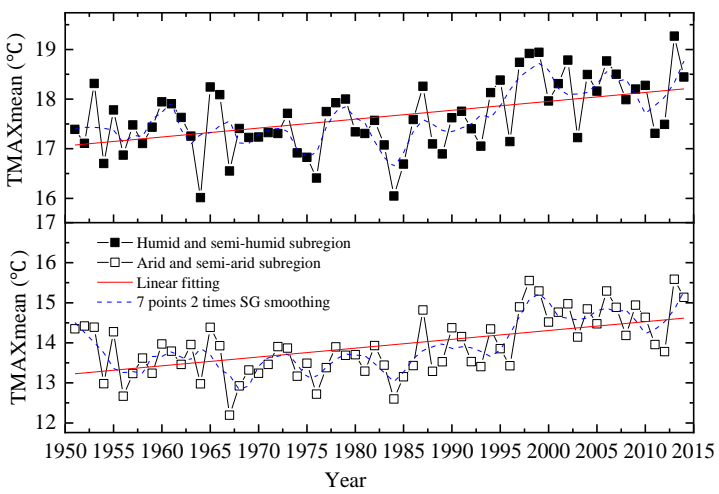

(c) Interannual variation of TMAXmean index

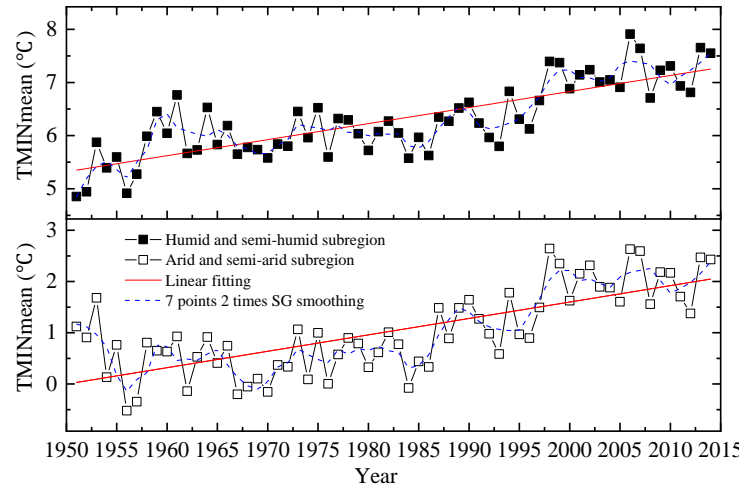

(e) Interannual variation of TMINmean index

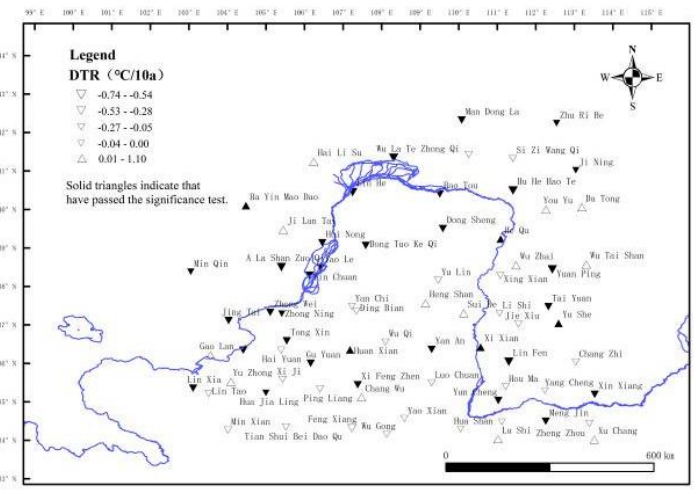

(b) Space variation of DTR index

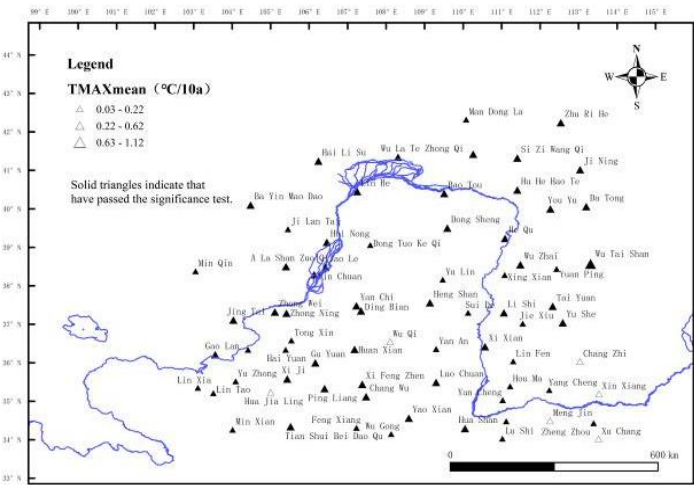

(d) Space variation of TMAXmean index

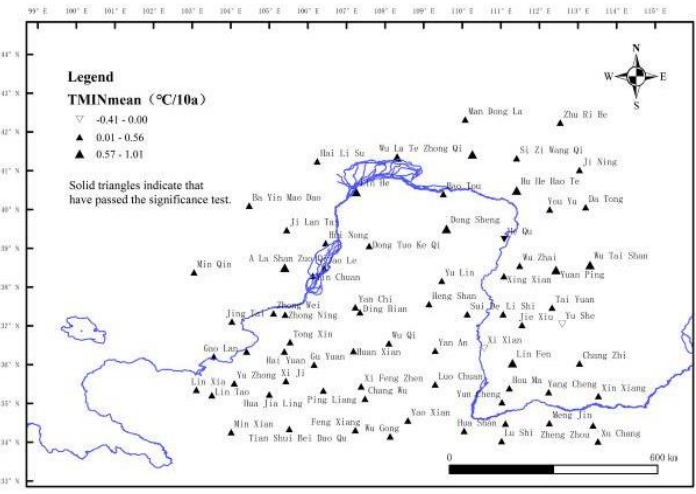

(f) Space variation of TMINmean index

Figure 4. Temporal and spatial variation of DTR, TMAXmean and TMINmean indexes 
It can be seen from Table 2 that the maximum values (including the extremely high value TNx of minimum temperature and extremely high value TXx of daily maximum temperature) and minimum values (including extremely low value $\mathrm{TNn}$ of daily minimum temperature and extremely low value TXn of daily maximum temperature) of extreme temperature show an upward trend. The minimum values have a higher rate of rise and $\mathrm{TNx}$ reaches the highest rate of rise in humid sub-region, that is, $0.6{ }^{\circ} \mathrm{C} / 10 \mathrm{a}$. However, the rate of rise of $\mathrm{TXx}$ is $0.1^{\circ} \mathrm{C} / 10 \mathrm{a}$ only, making it fail to pass the confidence level test.

Table 2. Variation trend (1) of extreme temperature indexes from 1951 to 2014

\begin{tabular}{c|c|c}
\hline \multirow{2}{*}{ Index name } & Arid sub-region & Humid sub-region \\
\cline { 2 - 3 } & Rate of change $\left({ }^{\circ} \mathbf{C} / \mathbf{1 0 a}\right)$ & Rate of change $\left({ }^{\circ} \mathbf{C} / 10 a\right)$ \\
\hline DTR & $-0.1^{* *}$ & $-0.1^{* *}$ \\
TMAXmean & $0.2^{* *}$ & $0.2^{* *}$ \\
TMINmean & $0.3^{* *}$ & $0.3^{* *}$ \\
TNn & $0.4^{* *}$ & $0.6^{* *}$ \\
TNx & $0.3^{* *}$ & $0.1^{* *}$ \\
TXn & $0.3^{*}$ & $0.4^{* * *}$ \\
TXx & $0.2^{*}$ & $0.1^{\text {n.s. }}$ \\
\hline
\end{tabular}

**It passed the $99 \%$ confidence level test. *It passed the $95 \%$ confidence level test. n.s. means that the variation trend is not significant

On time scale, it can be observed from 7 points 2 times SG smoothing line that TNn index tends to be upward on the whole except the decrease from 1951 to 1955 (see Fig. 5a); TNx index has risen significantly since 1951 and reached a peak in 1960, then went down around 1983 (more significant in humid sub-region) and showed a significant upward trend after 1983 (see Fig. 5c); TXn index decreased from 1951 to 1957, and then rose wavelike and showed a moderate upward trend after 2000 (see Fig. 5e). TXx index rose significantly around the period of 1951-1973, showed a moderate upward trend around the period of 1973-1989, then rose significantly from 1990 to 2000 and then regained a moderate upward trend after 2000 (see Fig. 5g).

From the perspective of spatial distribution, TNn and TNx indexes showed an upward trend in most regions, with a significant upward trend in northeastern Gansu, Ningxia, Linhe, Baotou and Hohhot, Inner Mongolia and Shanxi (see Fig. $5 b$ and $d$ ). TXn index showed a significant upward trend in the entire the middle reach of Yellow River with a larger range (see Fig. 5f). TXx index rose significantly in some areas such as northeastern Gansu, Inner Mongolia Bayinmaodao, Hohhot, Yuncheng, Shanxi and other areas, with a small range (see Fig. 5h).

As mentioned above, average maximum temperature and minimum temperature in the middle reach of Yellow River show a significant upward trend, the rate of rise of minimum is higher than that of maximum and daily temperature range shows a significant downward trend. Seeing from Interannual variation, TNx, TNx, TXn and TXx indexes in this area tends to be upward on the whole, but they are in stages: showed a downward trend around the period of 1951-1955, rapidly rose from 1956 to 2000 and slowed down after 2000. In addition to TNN index, the rate of change of other three indexes in the arid sub-region is higher than that in the humid sub-region. 


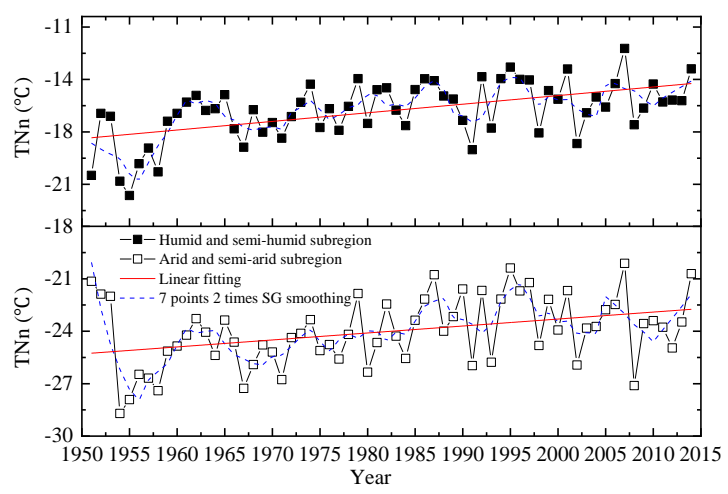

(a) Interannual variation of TNn index

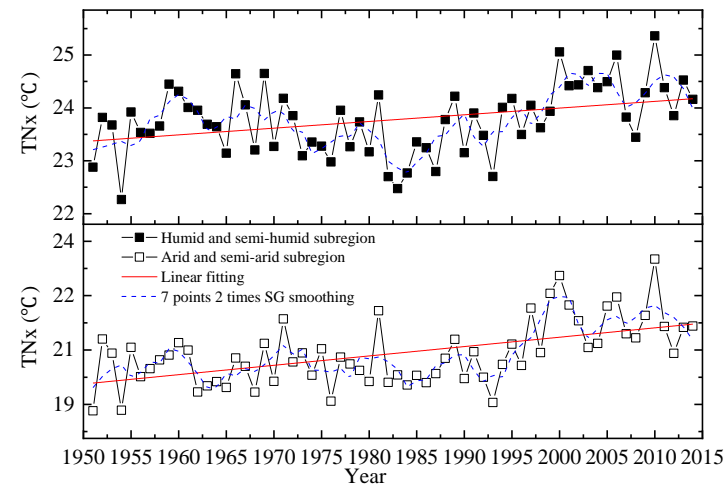

(c) Interannual variation of TNx index

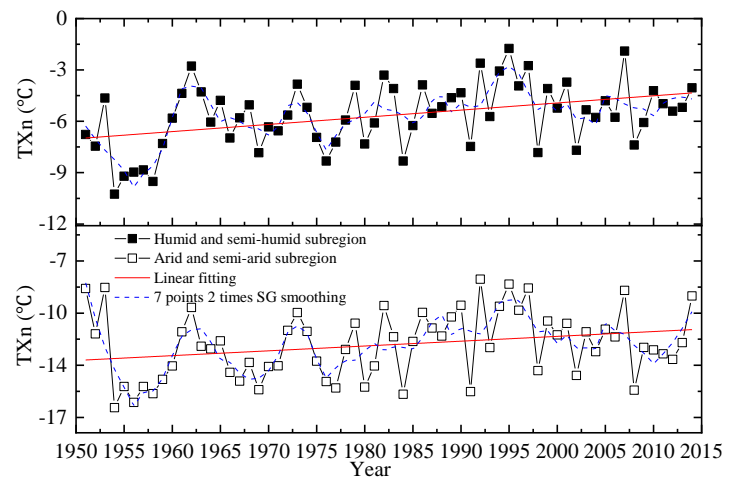

(e) Interannual variation of TXn index

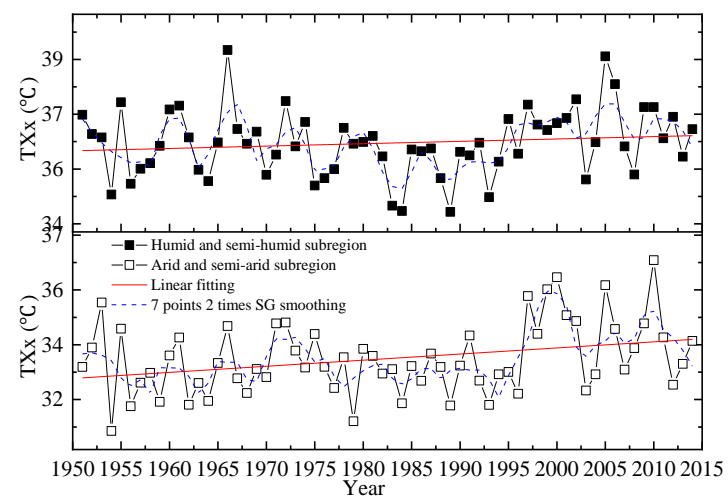

(g) Interannual variation of TXx index

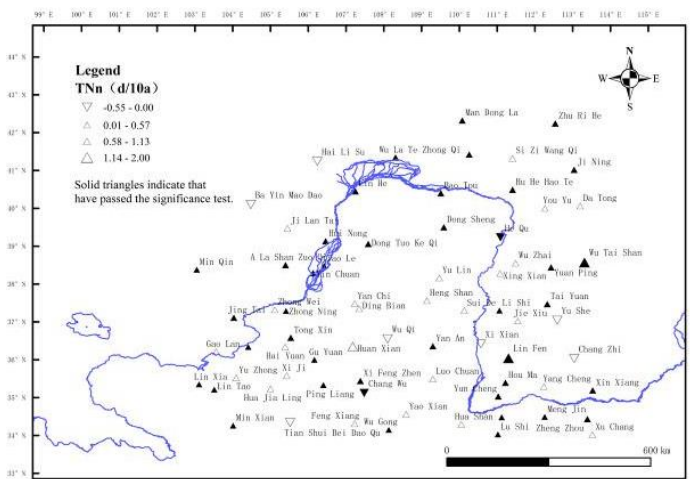

(b) Space variation of TNn index

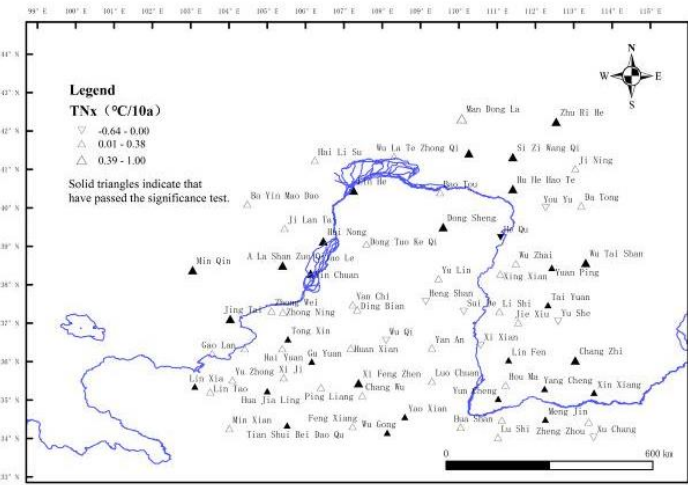

(d) Space variation of TNx index

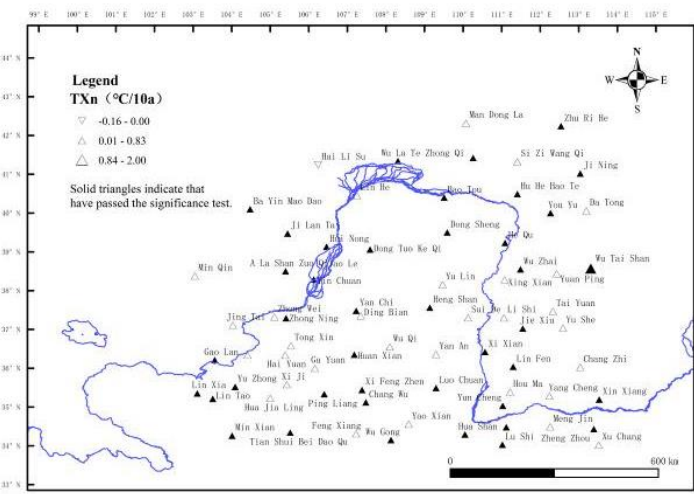

(f) Space variation of TXn index

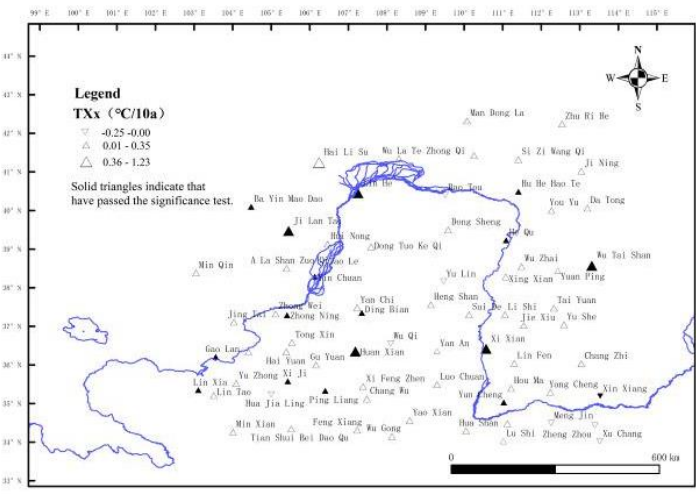

(h) Space variation of TXx index

Figure 5. Temporal and spatial variation of $T N n, T N x, T X n$ and $T X n$ indexes 
It is worth noting that the variation trend of 7 indexes analyzed above slowed down around 2000, which may be related to the slowdown of global warming. In addition, the timing of the slowdown analyzed in this paper is basically consistent with relevant research conclusions (Wang et al., 2014b, c, 2005; Chen et al., 2014).

\section{Variation of FDO, IDO, SU25, TN10p, TX10p, TR20, TN90p and TX90p indexes}

From time scale, the index FD0 number of frost days in the past 60 years and the index ID0 number of frozen days show a highly significant downward trend, of which the downward rate in humid sub-region is higher than that in arid sub-region. The downward rate of FD0 and ID0 indexes in humid sub-region is $-3.3 \mathrm{~d} / 10 \mathrm{a}$ and $-1.9 \mathrm{~d} / 10 \mathrm{a}$, respectively; while that in arid sub-region is $-2.6 \mathrm{~d} / 10 \mathrm{a}$ and $-1.5 \mathrm{~d} / 10 \mathrm{a}$, respectively (see Fig. $6 a$ and $c$ and Table 4). It is also noted that the index number of frozen days in arid sub-region showed an upward trend while a downward trend in humid sub-region from 1951 to 1963 . The index SU25 number of days in summer shows a significant upward trend, and the rate of change in arid sub-region and humid sub-region reaches up to $2.5 \mathrm{~d} / 10 \mathrm{a}$ and $1.3 \mathrm{~d} / 10 \mathrm{a}$, respectively, which indicates that the number of days in arid sub-region whose daily maximum temperature is above $25^{\circ} \mathrm{C}$ increases significantly, and the number of days in summer from a climate sense is on the rise (see Fig. $6 e$ ).

On spatial scale, the index FD0 number of frost days has been reduced by a large margin, the rate of change varied from -10.47 to $0 \mathrm{~d} / 10 \mathrm{a}$ and $90 \%$ of stations have passed the significance test. The index FD0 showed a slightly upward trend in only two stations, Yushe and Xixian, which may be individual abnormal stations, which cannot negate the overall upward variation trend of FD0 index in the middle reach of Yellow River. The index ID0 number of frozen days has also been reduced by a large margin, that is, $-9.62 \sim 0 \mathrm{~d} / 10 \mathrm{a}$, and $78 \%$ of stations have passed the significance test (see Fig. $6 \mathrm{~b}$ and $d$ ). The index SU25 number of days in summer at all meteorological stations showed an upward trend, of which $67 \%$ of stations showed a significant trend, mainly centralized in arid sub-region; while those stations without significant trend are centralized in humid sub-region. The analysis combined with Table 3 indicates that the upward trend of the index SU25 in humid sub-region is smaller (see Fig. 6f).

Table 3. Variation trend (2) of extreme temperature indexes from 1951 to 2014

\begin{tabular}{c|c|c}
\hline \multirow{2}{*}{ Index name } & Arid sub-region & Humid sub-region \\
\cline { 2 - 3 } & Rate of change (d/10a) & Rate of change (d/10a) \\
\hline FD0 & $-2.6^{* *}$ & $-3.3^{* *}$ \\
ID0 & $-1.5^{*}$ & $-1.9^{* *}$ \\
SU25 & $2.5^{* *}$ & $1.3^{*}$ \\
TN10p & $-2.2^{* *}$ & $-2.0^{* * *}$ \\
TX10p & $-1.0^{* *}$ & $-0.8^{* *}$ \\
TN90p & $1.4^{* *}$ & $1.4^{* *}$ \\
TR20 & $0.8^{* *}$ & $1.2^{* *}$ \\
TX90p & $0.9^{* *}$ & $0.6^{*}$ \\
\hline
\end{tabular}

**It passed the $99 \%$ confidence level test. *It passed the $95 \%$ confidence level test. n.s. means that the variation trend is not significant 


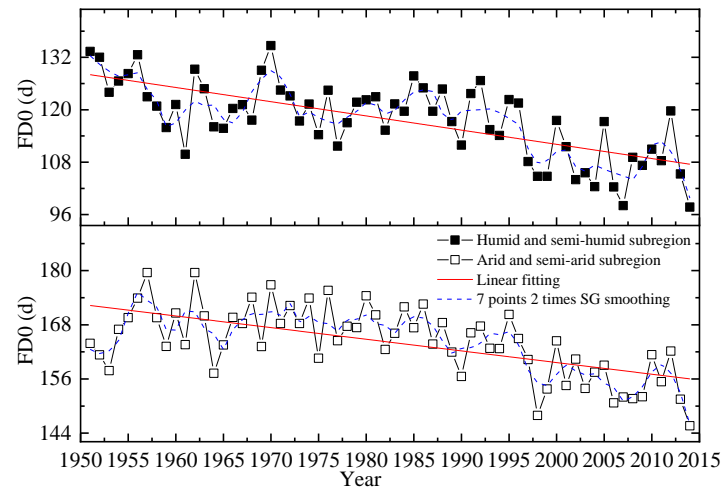

(a) Interannual variation of FD0 index

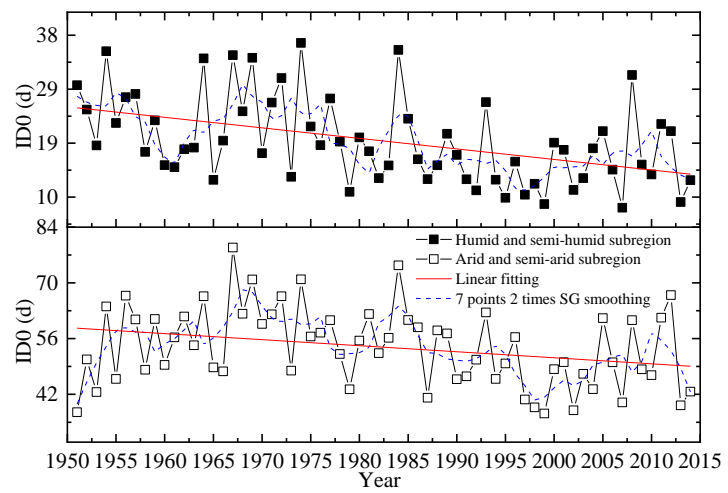

(c) Interannual variation of ID0 index

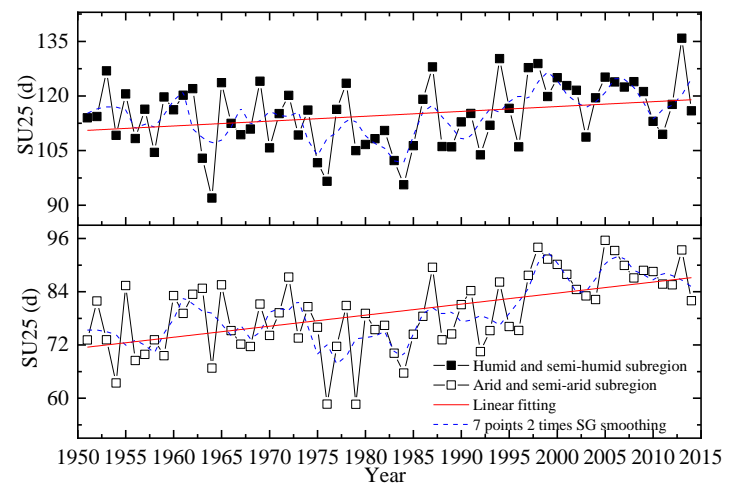

(e) Interannual variation of SU25 index

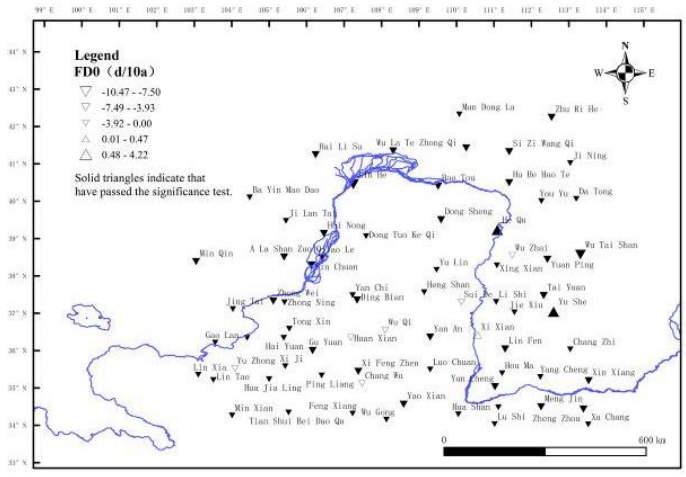

(b) Space variation of FD0 index

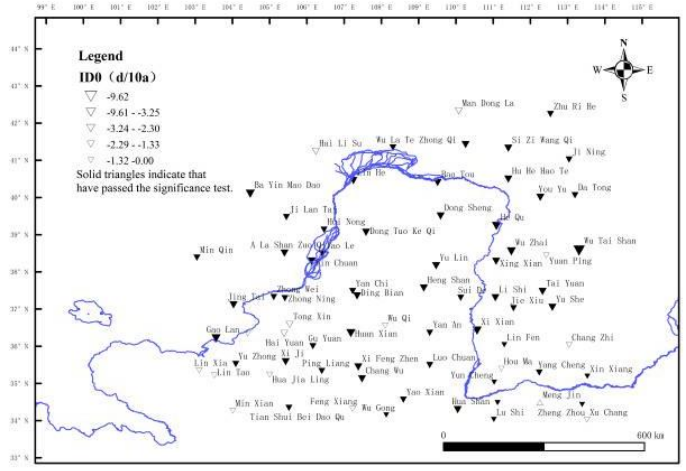

(d) Space variation of ID0 index

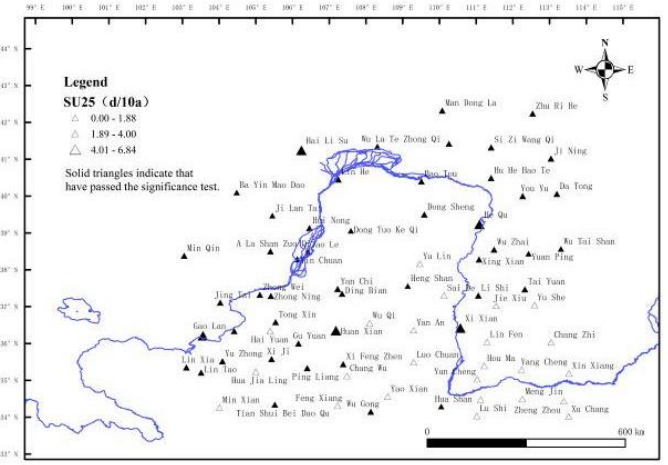

(f) Space variation of SU25 index

Figure 6. Temporal and spatial variation of FDO, IDO and SU25 indexes

On time scale, number of days with cold night TN10P and number of days with cold day TX10P showed a significant wavelike downward trend, and the rate in arid subregion is higher than that in humid sub-region (see Fig. 7a and c). Number of days with warm night TN90P, number of days with hot night TR20 and number of days with warm day TX90P showed a significant upward trend, and corresponding indexes in both arid and humid sub-regions have basically the same rate of change, but that is more significant in arid sub-region than humid sub-region, and the three indexes above have passed 99\% confidence test. From 7 points 2 times SG smoothing curve, it can be seen that TN90P, TR20 and TX90P indexes tend to rise in stages: The 3 indexes showed a extremely gentle upward trend from 1951 to 1985, but later showed a sharp upward trend (see Fig. 7e, g, $i$ and Table 3). 


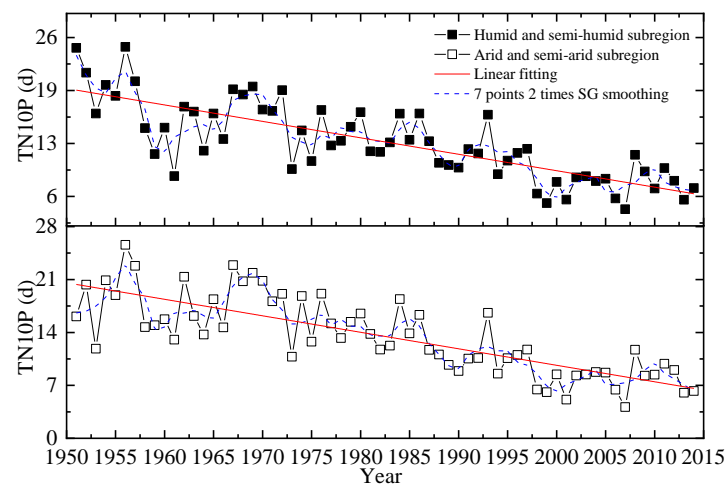

(a) Interannual variation of TN10P index

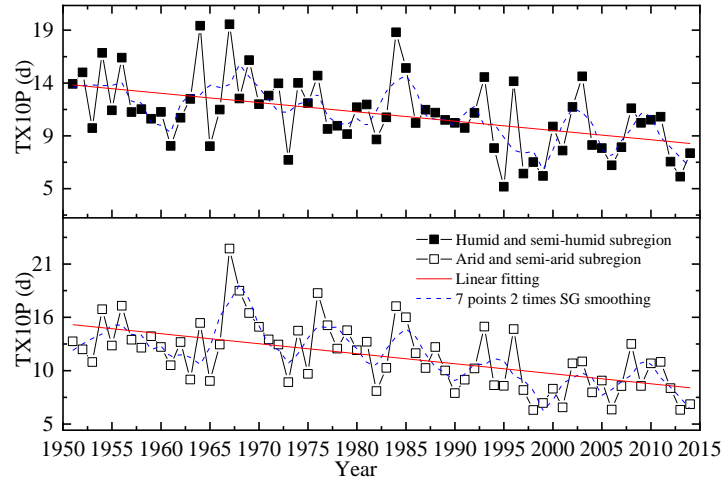

(c) Interannual variation of TX10P index

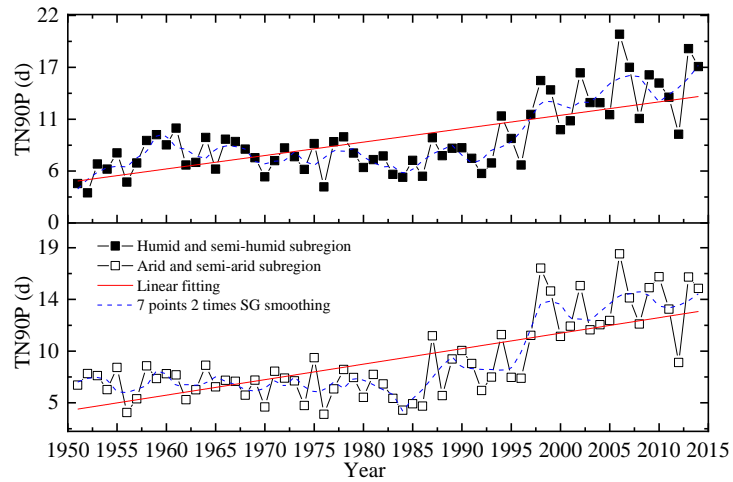

(e) Interannual variation of TN90P index

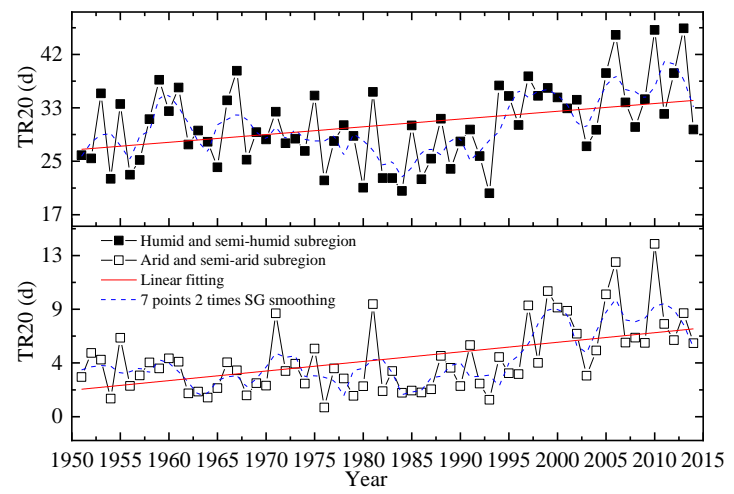

(g) Interannual variation of TR20 index

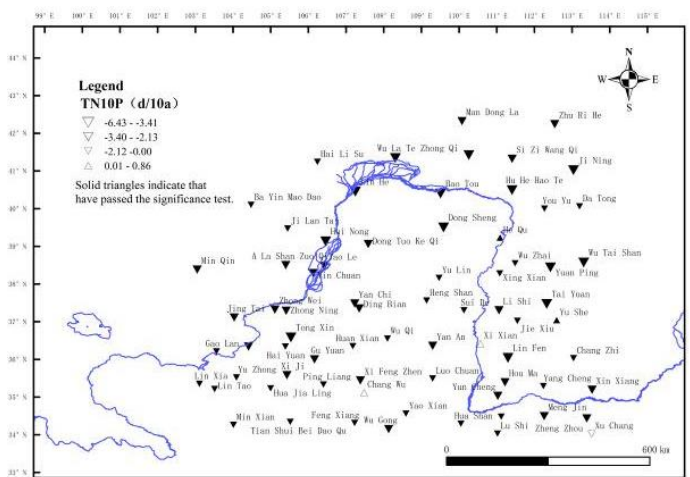

(b) Space variation of TN10P index

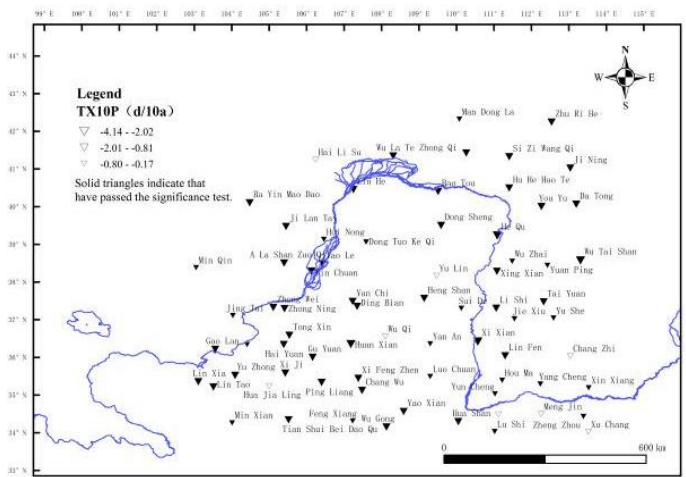

(d) Space variation of TX10P index

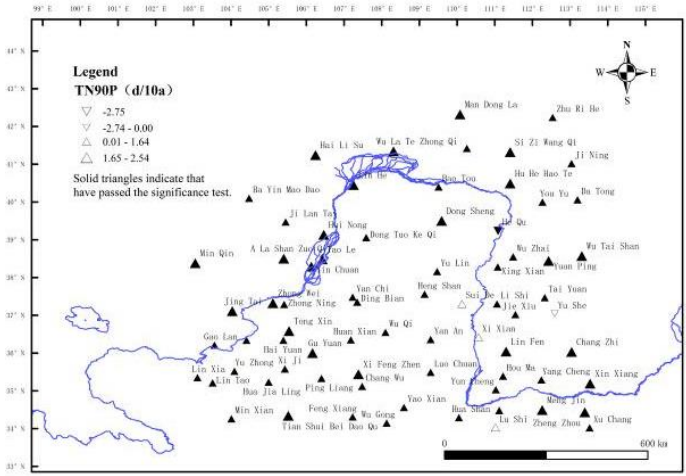

(f) Space variation of TN90P index

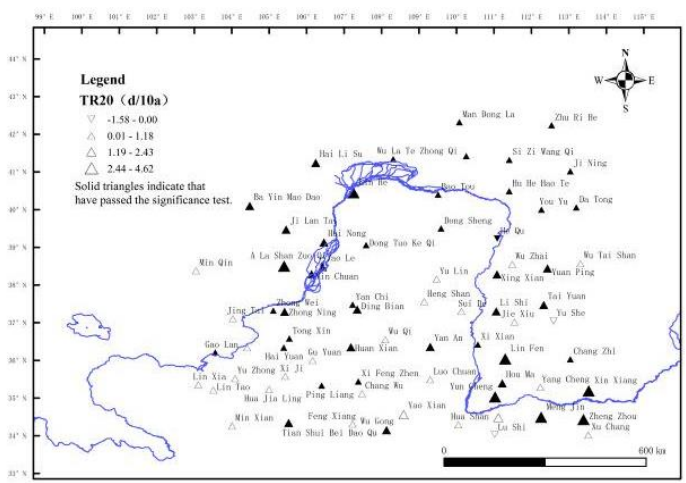

(h) Space variation of TR20 index 


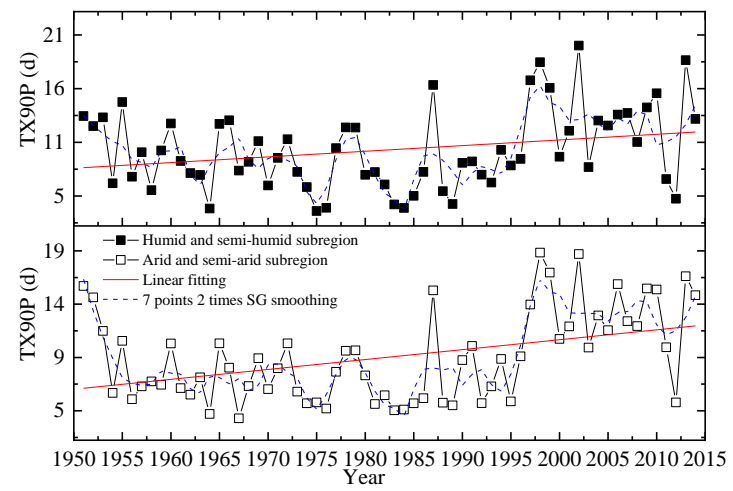

(i) Interannual variation of TX90P index

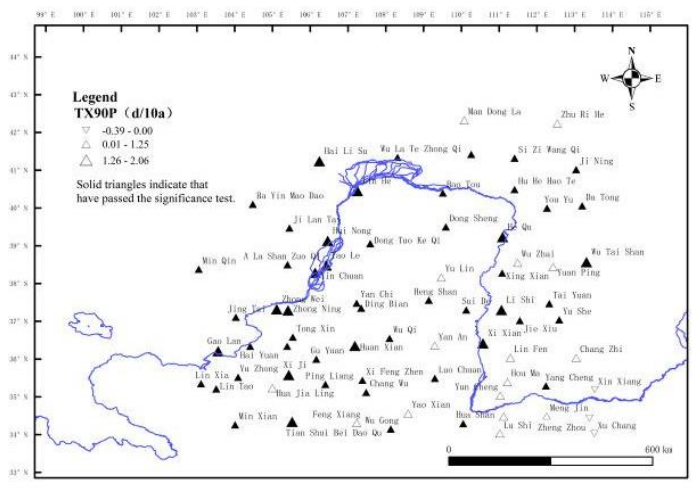

(j) Space variation of TX90P index

Figure 7. Temporal and spatial variation of TN10p, TX10p, TR20, TN90p and TX90p indexes

On spatial scale, TN10P and TX10P indexes decreased significantly, reaching $6.43-0 \mathrm{~d} / 10 \mathrm{a}$ and $-1.44-0 \mathrm{~d} / 10 \mathrm{a}$, respectively, and the proportion of stations passing the significance test reached $96 \%$ and $89 \%$, respectively. It shows that the number of days with cold night and number of days with cold day in the entire the middle reach of Yellow River has the consistent downward trend on spatial scale, but the variation is still more significant in arid sub-region than humid sub-region (see Fig. $7 b$ and $d$ ). TN90P index showed a significant upward trend, 95\% of the stations passed the significance test and only two stations in Hequ and Yushe showed a downward trend. TX90P index showed a significant upward trend in most areas of the middle reach of Yellow River, and the proportion of significant stations reached up to $74 \%$, mainly centralized in arid sub-region; Zhengzhou, Xinxiang, Mengjin and Xuchang in humid sub-region showed a downward trend. The space variation is inconsistent in the index TR20 number of days with hot night, and a significant upward trend has been found in northeastern Gansu, north-central part of Ningia, most parts of northern Shaanxi, Linhe, Baotou and Hohhot, Inner Mongolia, most parts of Shanxi and Zhengzhou, Henan. However, a downward trend can also be found in southeastern Gansu, southern Ningxia, Huashan in central Shaanxi, Siziwangqi and Jining, Inner Mongolia (see Fig. $7 f, h$ and $g$ ).

\section{Variation of WSDI, CSDI and GSL indexes}

Observed from time scale, the index of hot persistence WSDI increased significantly in arid sub-region with an increase rate of $0.7 \mathrm{~d} / 10 \mathrm{a}$, but the wavelike upward variation trend was not significant in humid sub-region (not passed the significance test). The index of cold persistence CSDI showed a downward trend, and the downward rate was similar in both arid and humid sub-regions, that is, $-2.0 \mathrm{~d} / 10 \mathrm{a}$ and $-1.9 \mathrm{~d} / 10 \mathrm{a}$, respectively, which indicates from different angles that the warming is significant in the middle reach of Yellow River. The index GSL crop growth period showed a significant upward trend on the whole, and the rate of rise in humid subregion is much higher than that in arid sub-region, which is $2.6 \mathrm{~d} / 10 \mathrm{a}$ (see Fig. $8 a, c, e$ and Table 4).

Observed from spatial scale, WSDI index showed an overall upward trend, and $53 \%$ of the stations passed the significance test. However, WSDI index showed a downward trend in Minxian County and Huajialing, Gansu, Guyuan and Haiyuan, 
Ningxia, Zhengzhou, Xinxiang and Xuchang, Henan, which may be caused by local microclimate and other factors, but the specific reasons need to be further studied (see Fig. 8b). CSDI index showed a consistent downward trend on the whole in space, but the downward rate varied from 09.74 to $0 \mathrm{~d} / 10 \mathrm{a}$, and $71 \%$ of the stations passed the significance test (see Fig. 8d). GSL index showed a consistent upward trend on the whole in space, but the rate varied from 0.1 to $14.04 \mathrm{~d} / 10 \mathrm{a}$, and $78 \%$ of the stations passed the significance test. In addition, Yushe is the only station where showed a downward trend, which was not significant (see Fig. 8f).

Table 4. Variation trend (3) of extreme temperature indexes from 1951 to 2014

\begin{tabular}{c|c|c}
\hline \multirow{2}{*}{ Index name } & Arid sub-region & Humid sub-region \\
\cline { 2 - 3 } & Rate of change (d/10a) & Rate of change (d/10a) \\
\hline WSDI & $0.7^{* *}$ & $0.6^{\text {n.s. }}$ \\
CSDI & $-2.0^{* *}$ & $-1.9^{* *}$ \\
GSL & $2.6^{* *}$ & $6.8^{* *}$ \\
\hline
\end{tabular}

**It passed the $99 \%$ confidence level test. *It passed the $95 \%$ confidence level test. n.s. means that the variation trend is not significant

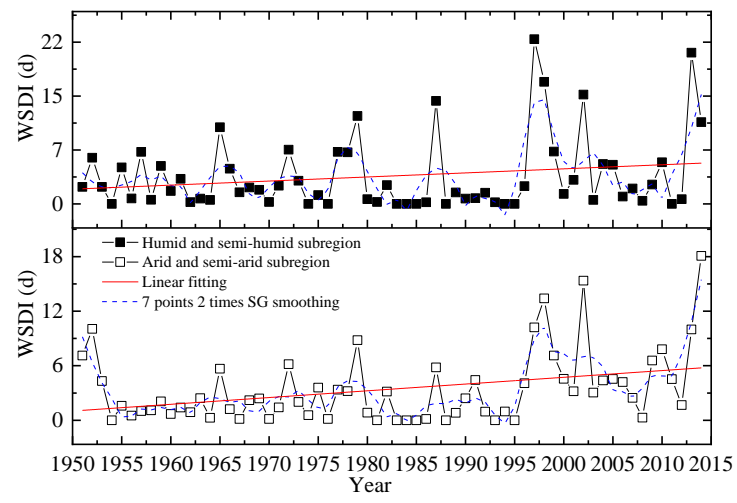

(a) Interannual variation of WSDI index

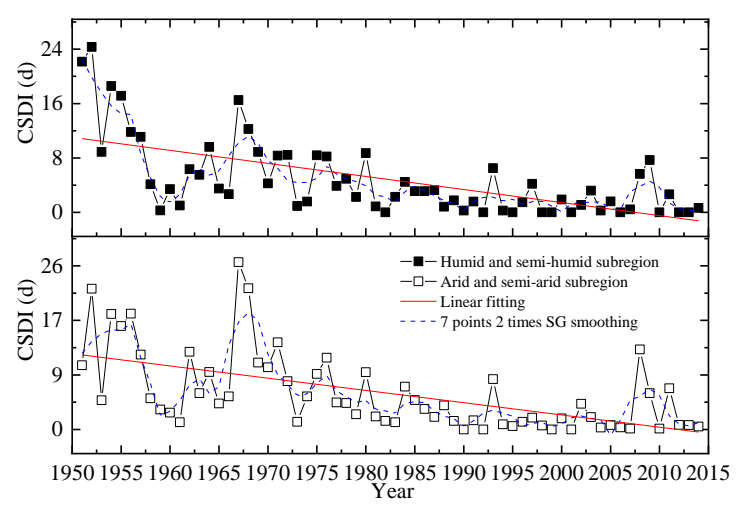

(c) Interannual variation of CSDI index

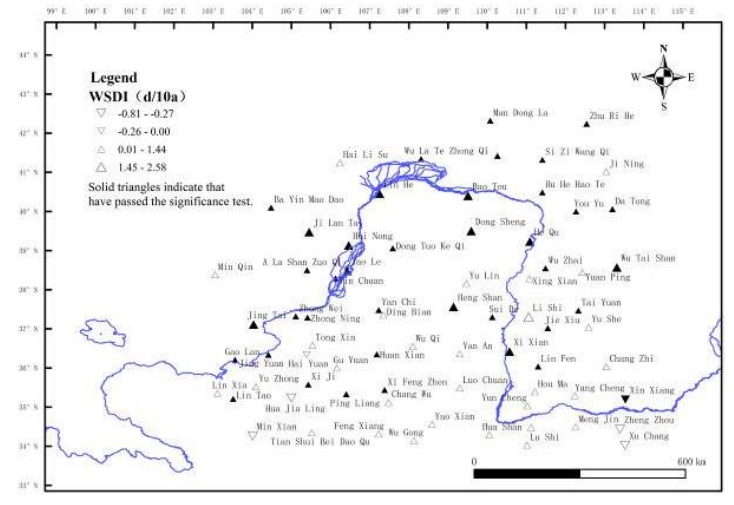

(b) Space variation of WSDI index

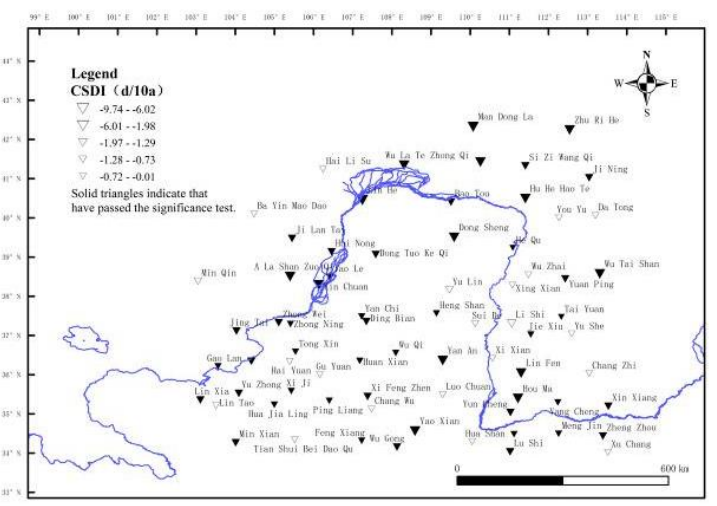

(d) Space variation of CSDI index 


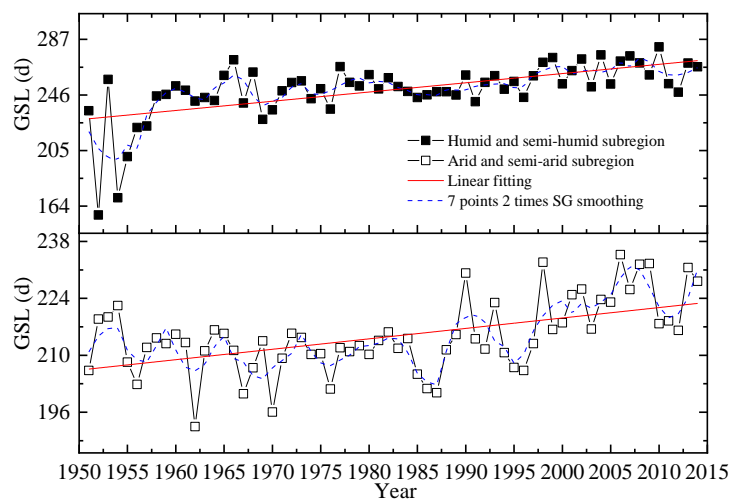

(e) Interannual variation of GSL index

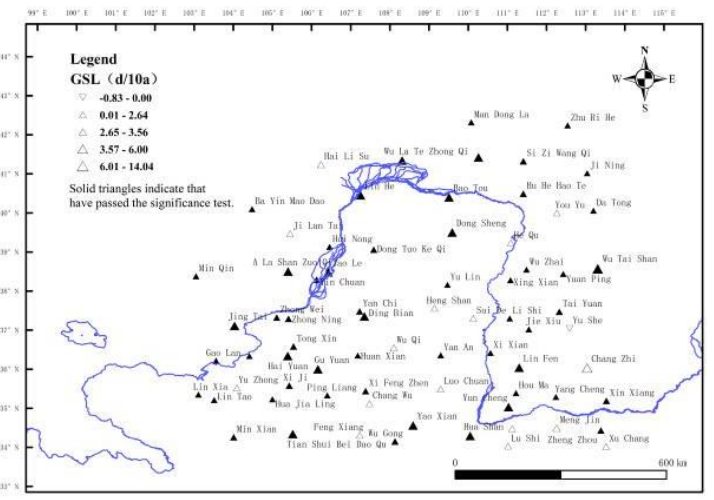

(f) Space variation of GSL index

Figure 8. Temporal and spatial variation of WDSI, CSDI and GSL indexes

\section{Conclusion}

This study analyzes the spatial-temporal scale of 18 extreme temperature indexes in the middle reach of Yellow River from 1951 to 2014, and draws the following conclusions:

(1) The middle reach of Yellow River is located in the transitional zone of arid and semi-arid and humid and semi-humid climate in China. The arid and semi-arid subregion (located in the upper reaches of the Yellow River) and humid and semi-humid sub-region (located in the middle and lower reaches of the Yellow River) in the middle reach of Yellow River have basically similar variation trend in terms of extreme temperature events, but the intensity is different and spatial distribution is inconsistent.

(2) On time scale, it is found through the analysis of 18 extreme temperature indexes that the extreme temperature events have shown an upward trend in the past 60 years. On spatial scale, the distributional difference of each index is significant. The variation rate of multiple indexes in arid sub-region is greater than that in humid sub-region. The proportion of meteorological stations with significant variation of each index in arid sub-region is higher than that in humid sub-region. In addition, some indexes such as DTR, TNx, TNx, TXx, WSDI and TX90p has a different variation trend from the entire the middle reach of Yellow River in individual small areas, which may be caused by local microclimates in urban heat islands and hilly areas, but further analysis and verification is also required.

(3) The variation trend of indexes such as DTR, TMAXmean, TMINmean, TNn, TNx, TXx and TXx began to slow down around 2000, which may be related to the slowdown of global warming (hiatus phenomenon). The time of slowdown analyzed in this paper is basically consistent with the conclusions of relevant researches. Regarding the impact of the slowdown of global warming on extreme temperature events, the changes in extreme temperature events around the slowdown of global warming may also be further studies.

Compared with the research results of the approximate region (Zhou et al., 2011; Ma et al., 2003; Li et al., 2010; Ren et al., 2014), this study believes that the extreme temperature events in the middle reaches of the Yellow River are on the rise. This may be the product of global climate change in recent decades. Therefore, changes in extreme temperature events may have many adverse effects on the development of the 
region, and appropriate measures should be considered to protect future ecological and agricultural sustainability, as well as human security.

Acknowledgements. This study was funded by "Major Innovation Projects for Building First-class Universities in China's Western Region"(Grant No. ZKZD2017002); the university first-class discipline construction project of Ningxia, China. (Grant No. NXYLXK2017A03); the Natural Science Foundation of Ningxia, China (Grant No. 2019AAC03049); the scientific research project of Ningxia Colleges and Universities (Grant No. NGY2017026) and the China Scholarship Council (Grant No. 201708645016).

\section{REFERENCES}

[1] Alexander, L. V. (2016): Global observed long-term changes in temperature and precipitation extremes: a review of progress and limitations in IPCC assessments and beyond. - Weather and Climate Extremes 11: 4-16.

[2] Cai, T., Tang, H. (2011): A survey of least squares fitting principles for smoothing filters: Savitzky-Golay. - Digital Communication 01: 63-68 + 82.

[3] Chen, L., Wang, S., Shang, K., et al. (2011): Atmospheric circulation anomalies of largescale extreme high temperature events in Northwest China. - Journal of Desert Research 04: 1052-1058.

[4] Chen, S., Wang, J., Guo, J., et al. (2012): Evolution characteristics of the extreme high temperature event in Northwest China from 1961 to 2009. - Journal of Natural Resources 05: 832-844.

[5] Chen, X., Cai, Y., Tan, J., et al. (2014): Research progress on hiatus in the process of global warming. - Advances in Earth Science (08): 947-955.

[6] Diffenbaugh, N. S., Singh, D., Mankin, et al. (2017): Quantifying the influence of global warming on unprecedented extreme climate events. - Proceedings of the National Academy of Sciences 114(19): 4881-4886.

[7] Grotjahn, R., Black, R., Leung, R., et al. (2016): North American extreme temperature events and related large scale meteorological patterns: a review of statistical methods, dynamics, modeling, and trends. - Climate Dynamics 46(3-4): 1151-1184.

[8] Horton, D. E., Johnson, N. C., Singh, D., et al. (2015): Contribution of changes in atmospheric circulation patterns to extreme temperature trends. - Nature 522(7557): 465.

[9] Li, Y., He, D., Hu, J., et al. (2012): Spatial and temporal variations of extreme precipitation events in the Red River Basin during 1960-2007. - Journal of Natural Resources (11): 1908-1917.

[10] Li, Z., Zheng, F. L., Liu, W. Z., et al. (2010): Spatial distribution and temporal trends of extreme temperature and precipitation events on the Loess Plateau of China during 19612007. - Quaternary International 226(1-2): 92-100.

[11] Li, Z., Li, C., Song, J., et al. (2015): An analysis of the characteristics and causes of extremely high temperature days in the Yangtze-Huaihe River basins in summer 19602011. - Climatic and Environmental Research 20(5): 511-522.

[12] Mooshammer, M., Hofhansl, F., Frank, A. H., et al. (2017): Decoupling of microbial carbon, nitrogen, and phosphorus cycling in response to extreme temperature events. Science Advances 3(5): e1602781.

[13] Ma, G., Rudolf, V. H., Ma, C. S. (2015): Extreme temperature events alter demographic rates, relative fitness, and community structure. - Global Change Biology 21(5): 17941808.

[14] Ma, Z. G., Fu, C. B., Ren, X. B., et al. (2003): Trend of annual extreme temperature and its relationship to regional warming in northern China. - Acta Geographica Sinica 58(Supplement 1): 11-20. 
[15] Nie, J., Stevens, T., Rittner, M., Stockli, D., Garzanti, E., Limonta, M., ... Lu, H. (2015): Loess plateau storage of northeastern Tibetan plateau-derived Yellow River sediment. Nature Communications 6: 8511.

[16] Qi, T., Zhang, Q., Wang, Y., et al. (2015): Spatiotemporal patterns of pan evaporation in spatiotemporal patterns of pan evaporation in 1960--2005 in China: changing properties and possible causes in China. - Scientia Geographica Sinica 12: 1599-1606.

[17] Ren, G., Zhou, Y. (2014): Urbanization effect on trends of extreme temperature indices of national stations over Mainland China, 1961-2008. - Journal of Climate 27(6): 23402360.

[18] Shen, H., Ma, M., Wang, J., et al. (2012): Variation characteristics of extreme air temperature events in Qinghai Province. - Journal of Glaciology and Geocryology 06: 1371-1379.

[19] Tang, T., Jin, R., Peng, X., et al. (2014): Analysis on extremely high temperature over southern China in summer 2013. - Meteorological Monthly 10: 1207-1215.

[20] Wang, L., Liu, T., Ding, Y., et al. (2016): Characteristics and tendency of climate change in the Hetao irrigation district in the past 50 years. - Journal of Beijing Normal University (Natural Science) 03: 402-407.

[21] Wang, Q., Zhang, M., Wang, S., et al. (2013): Extreme temperature events in Yangtze River Basin during 1962-2011. - Acta Geographica Sinica 05: 611-625.

[22] Wang, S., Luo, Y., Zhao, Z., et al. (2005): Controversy about climate warming. Progress in Natural Science 08: 917-922.

[23] Wang, S., Luo, Y., Zhao, Z., et al. (2014a). Climate science challenges. - Advances in Climate Change Research 04: 306-309.

[24] Wang, S., Luo, Y., Zhao, Z., et al. (2014b). How long will the pause of global warming stay again? - Progressus Inquisitiones de Mutatione Climatis (06): 465-468.

[25] Wang, S., Luo, Y., Zhao, Z., et al. (2014c). Pause for thought. - Progressus Inquisitiones de Mutatione Climatis (04): 303-306.

[26] Wang, Y., Tan, D., Zhao, H. (2012): Characteristics of extreme high temperature in gansu in recent 50 Years. - Journal of Arid Meteorology 03: 410-414.

[27] Zhai, P., Pan, X. (2003): Change in extreme temperature and precipitation over Northern China during the second half of the 20th century. - Acta Geographica Sinica (S1): 1-10.

[28] Zhao, C., Chen, Y., Wang, W., et al. (2015): Temporal and spatial variation of extreme precipitation indexes of the Yellow River Basin in recent 50 years. - Yellow River 01: 18-22.

[29] Zhang, S. (2014): A new international climate change benchmark was officially opened in 2015. - Advances in Earth Science 08: 967.

[30] Zhang, Z., Chen, Y., Zhou, H. (2014): Spatiotemporal features of extreme high temperature in summer half year in Hetao and its vicinity. - Journal of Natural Disasters 02: 190-197.

[31] Zhou, Y., Ren, G. (2010): Variation characteristics of extreme temperature indices in mainland China during 1956-2008. - Climatic and Environmental Research 15(4): 405417.

[32] Zhou, Y., Ren, G. (2011): Change in extreme temperature event frequency over mainland China, 1961-2008. - Climate Research 50(2-3): 125-139. 